\title{
Fourth greek Christian epitaphs from Egypt
}

\section{A fourth greek Christian epitaphs from Egypt}

The date of the inscription is hard to fix precisely, the letter forms in combination with its Christian character indicating only that most probably it was cut in a period ranging from the $3^{\text {rd }}$ to $5^{\text {th }}$ cent A.D .

1-The text consists of six lines in capital letters. The measurements in c.m of the piece as a whole are 68.8 high by 42.8 wide by 15.8 ,

The stela has the shape of a human being without hands and legs. It has a human head facing forward inside a framework that has the shape of a balloon or electric bulb. The base facing downward and has the shape a triangle. The eyes are wide and bulging they do not look like real eyes. They take the shape of 2 circles where in the center has 2 pupils representing the eyes. The nose is short and it is located. It does not look like a real nose. The eats are protruding and are inaccurate. The mouth looks like a crescent. The body is rectangular. They are 6 lines inscribed from the personal features is the slela, it can be inferred that it belongs to a middle aged man although it is not mentored in the inscription conclude from the features of the face that it dates back to the $4^{\text {th }}$. Century AD.

\section{Text}

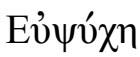

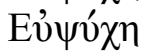

Movбทิৎ

oủsic

$\dot{\alpha} \theta \alpha ́ v \alpha-$

$\tau \mathrm{\tau} \uparrow \dagger$

Be brave Muses, nobody (is) immortal.

2-The text consists of 8 lines in capital letters. The measurements in c.m of the piece as a whole are 88.8 high by 42.8 wide by 15.8 ,

The stela has the shape of a human body with the head of an old dignified man that has a short beard with a consistent pattern.

The face is ova and the eyes are close-set narrow eyes. The nose is on the forehead with a small open mouth. The body of stela is rectangular. There are 10 lines inscribed in Greek letters on it. The base is of stela has a small protruded shape that is almost the same size of the head.

\section{2- The Text:}

$1-\varepsilon v \jmath \mu v ́-$

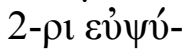

$3-\chi \imath$ oủ-

$4-\delta \grave{i c} \dot{\alpha}-$

5- $\theta \alpha \dot{v} \alpha-$

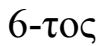

7-† $\mathrm{M} \alpha-$

8- $\rho i ́ \alpha+$

Be brave,keep courage, nobody (is) immortal. 


\section{Fourth greek Christian epitaphs from Egypt}

3-The text consists of 8 lines in capital letters. The measurements in c.m of the piece as a whole are 88.8 high by 52.8 wide by 14.7 ,

The upper part of stela has an oblique fame representing a young man's face. It is oval in shape. The eyes are wide and the nose is small. The lips seem to have a smile, the chin is long. The body of stela shows is rectangular in shape. The are 5 lines scraped on the body Greek letters, at the bottom there is a cross the base of the stela is protruded and it is slightly larger than the size of the head.

\section{3-The text:}

$1-\varepsilon v ่ \mu u ́ \rho 1$

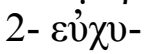

$3-\mu 1 \pi о \kappa \alpha$

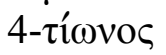

5-ov̉dic $\dot{\alpha} \theta-$

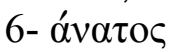

Be brave,Pocationos nobody (is) immortal.

4-The text consists of 7 lines in capital letters. The measurements in c.m of the piece as a whole are 78.3 high by 45.6 wide by 16.3 ,

The upper part of the stela is a rectangular frame. In it there is head. From the front, the face is oval get the features are not clear. The body has a rectangular shape with 8lines inscribed on it in Greek letters. At the bottom of it there is a Coptic Cross. The base is not found.

\section{Text:}

$1-\varepsilon \cup ̉ o \mu$

2-ıр Н

3- $v$ oủdì

4-c $\dot{\alpha} \theta \dot{\alpha} v-$

$5-\alpha \nu \tau 0_{-}$

$6-\varsigma \dot{\varepsilon} \tau \hat{\omega} v$

$7-\lambda \gamma+$

Be brave Hron, nobody (is) immortal.

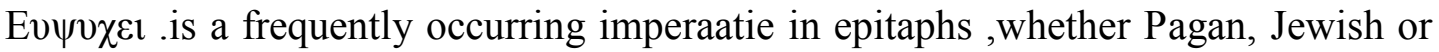
Christian ;It alternates with similar encouragements such as ; $\theta \alpha \rho \sigma \varepsilon 1, \varepsilon v \theta 0 \mu \varepsilon 1$ and Evppove1 and its purpose is to encourage the deceased who now has entered an

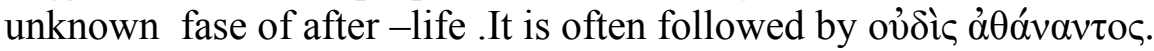

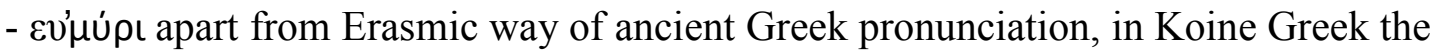
diphthong 'ot' looks like ' $\varepsilon 1, \eta, \imath, o l, v . . \kappa \tau \lambda$.' in pronunciation. That is the same way of pronunciation modern Greek. It is one of the most common orthographical mistakes in both Koine and modern Greek to interchange 'ee' sounds. So, one may assume that or

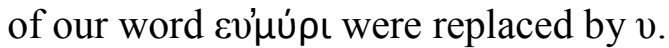

Another common mistake is to decline first and second declensions in the third

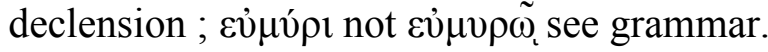

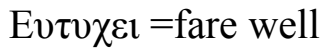




\section{Fourth greek Christian epitaphs from Egypt}

Ev $\psi v \chi \varepsilon 1$, isa frequenly occurring imperative in epitaphs, whether Pagan,Jewish or Christian .It alternates with similar encouragements such as $\varepsilon v \theta v \mu \varepsilon 1$ and $\varepsilon v \varphi \rho o v \varepsilon 1$, and its purpose is to encourage the deceased who now has entered an unknown

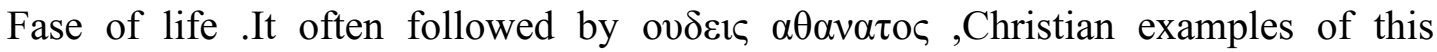
combination occur also in Rome.

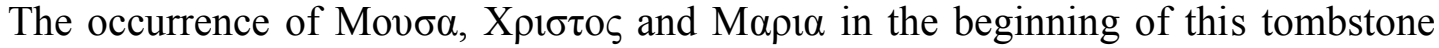
between two crosses is very perplexing. One may think that the dead person was a Jew then became a Christian that is why he mentioned Moses and then the Christ and his Holy Mother. The second alternative is that because he is a Christian, he believes in Moses and his holy book, the Old Testament as well as the Holy book of the Christ, the New Testament. The third alternative is that name of the dead is Moses, asking for blessing from both the Christ and his Holy Mother Mariam.

\section{Mohamed kashaf}


Fourth greek Christian epitaphs from Egypt

1

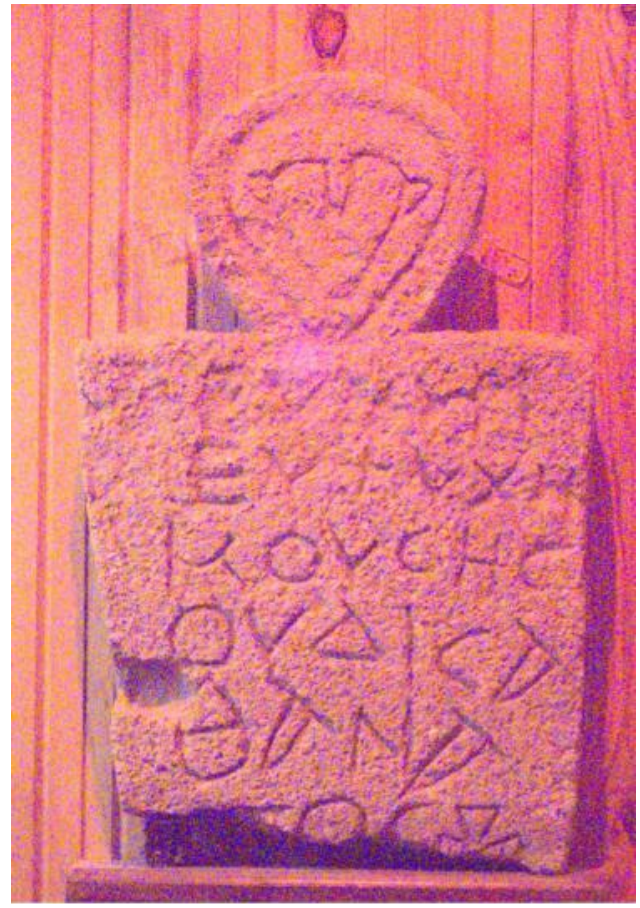

2

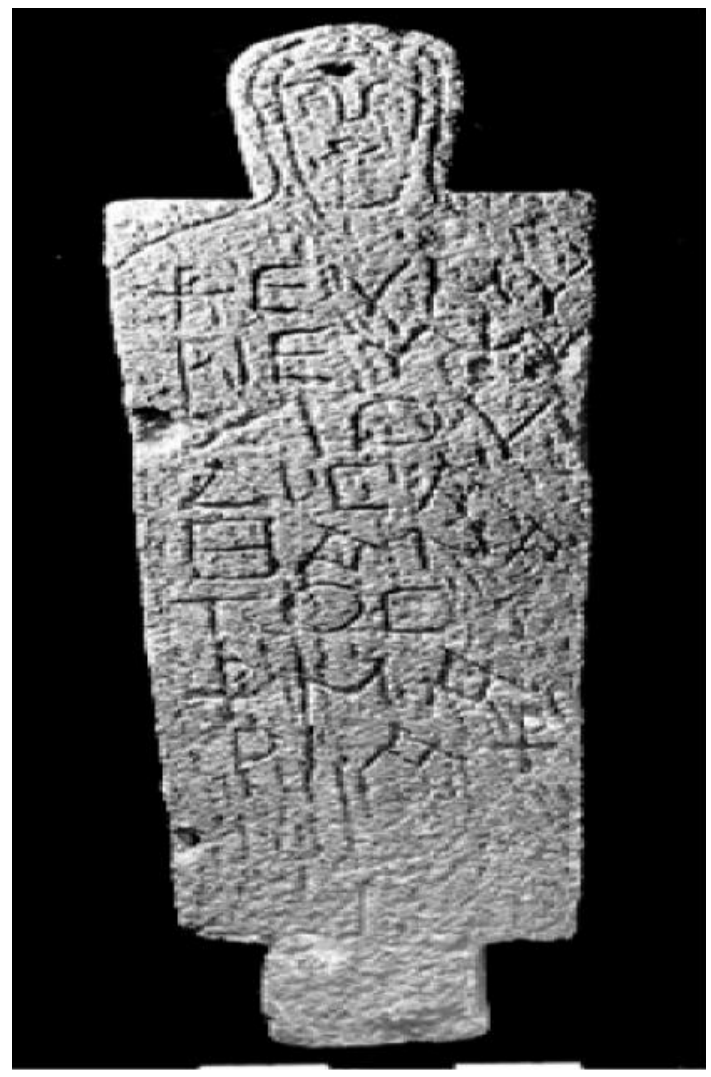


Fourth greek Christian epitaphs from Egypt

3

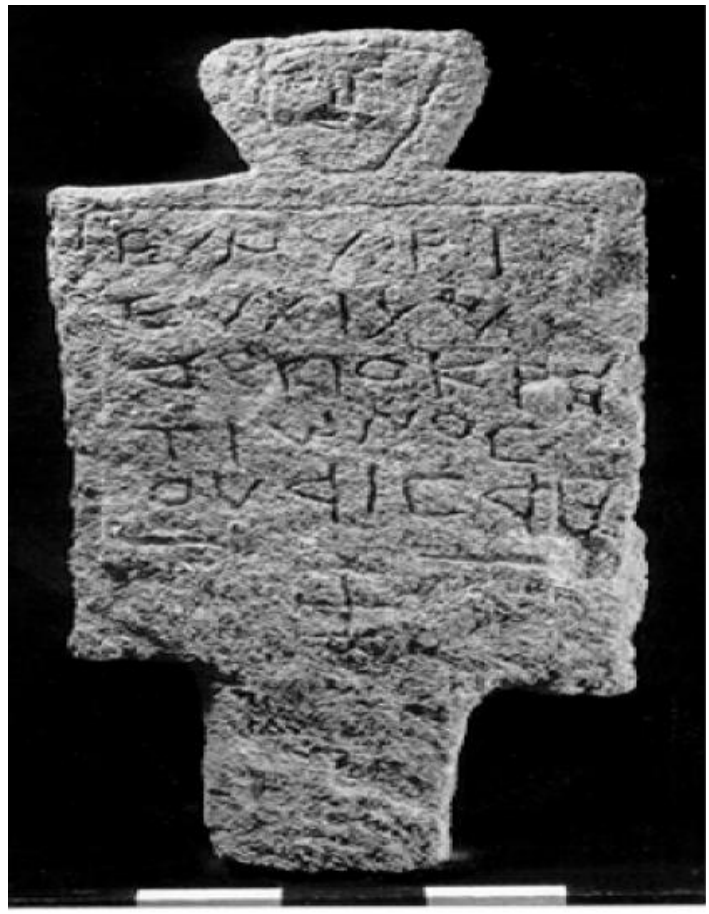

4

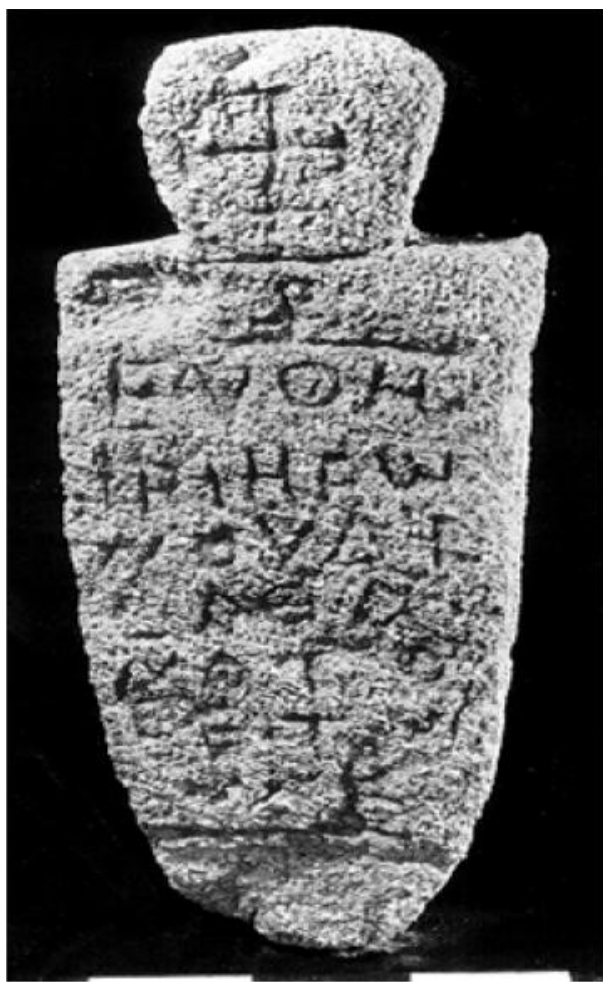

